\title{
Cellular Modelling of Secondary Radial Growth in Conifer Trees: Application to Pinus radiata (D. Don)*
}

Loïc Forest ${ }^{\mathrm{a}}$, Jacques Demongeot ${ }^{\mathrm{a}, \mathrm{b}}$

${ }^{a}$ Laboratoire Techniques de l'Imagerie, de la Modélisation et de la Cognition (TIMC UMR CNRS 5525), Institut de l'Ingénierie et de l'Information de Santé, Faculté de Médecine, 38706 La Tronche Cedex, France

${ }^{b}$ Institut Universitaire de France, France

Published online: 13 March 2007

(C) Society for Mathematical Biology 2007

In the html abstract portion of the online publication of "Cellular Modelling of Secondary Radial Growth in Conifer Trees: Application to Pinus radiata (D. Don)" (DOI: 10.1007/s11538-005-9004-5), the last name of the second author was mistakenly misspelled. The authors' names should have appeared as above. Springer regrets the error.

*The online version of the original article can be found at http://dx.doi.org/10.1007/s11538-0059004-5 